\title{
Explanati Comparison of Health Promoting Lifestyle and Self-Efficacy in Female Students With and Without Primary Dysmenorrhea \\ on
}

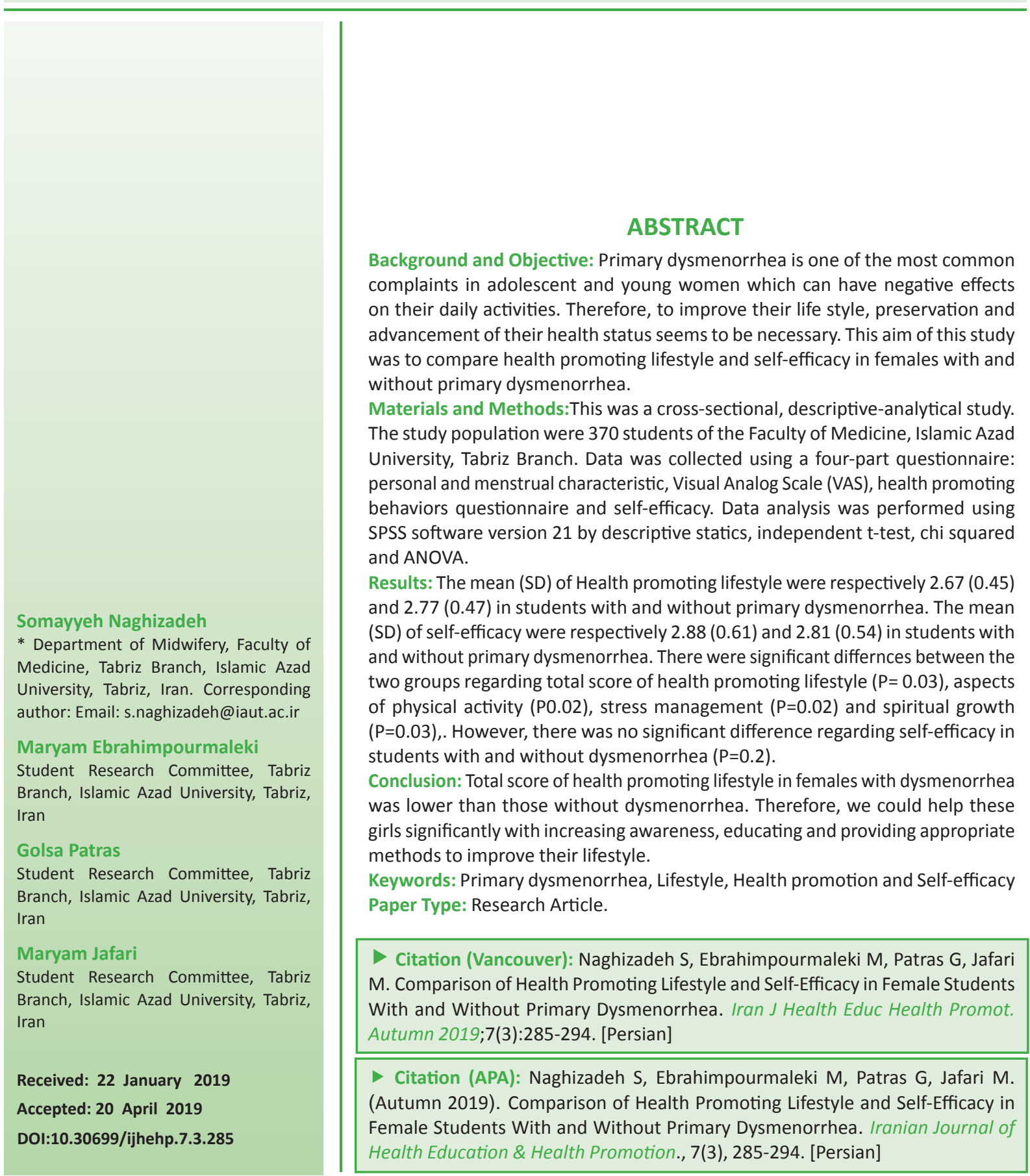




\title{
مقايسه سبكى زندكى ارتقادهنده سلامت و خودكارآمدى در دانشجويان دختر
}

\author{
مبتلا و غيرمبتلا به ديسمنوره اوليه
}

\section{بكيله}

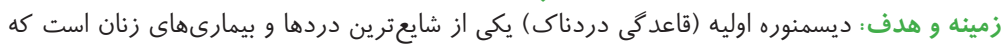

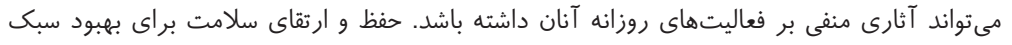

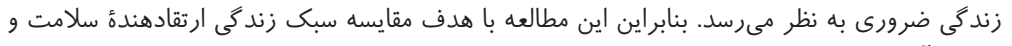

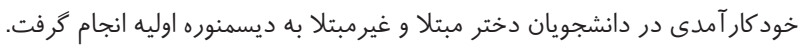

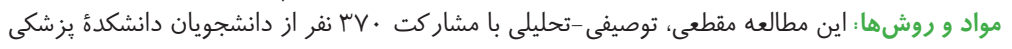

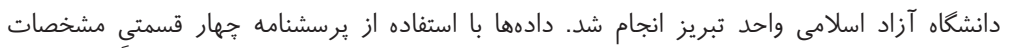

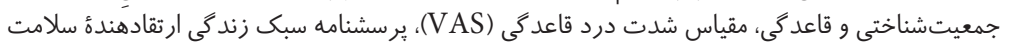

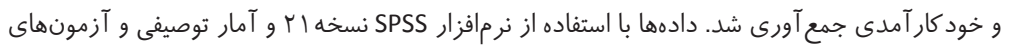

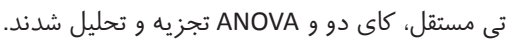

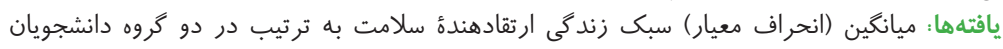

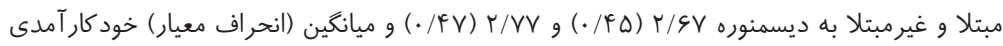

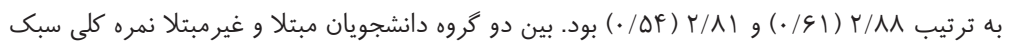

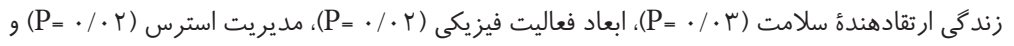

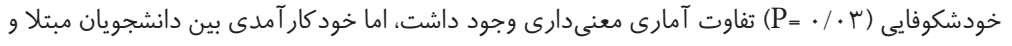

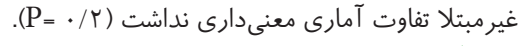

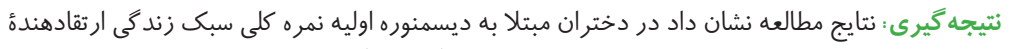

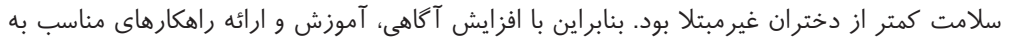

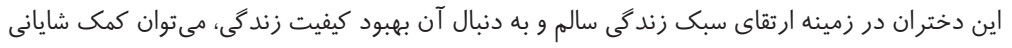
به اين افراد كرد.

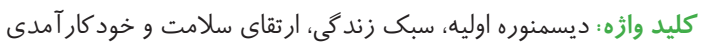
نوع مقاله : مطالعه يزوهشى.

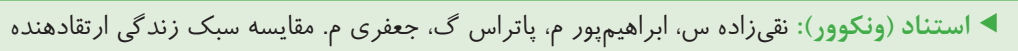

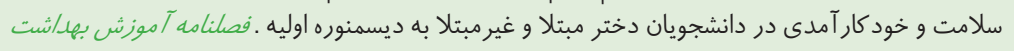

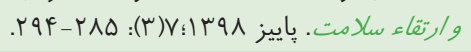

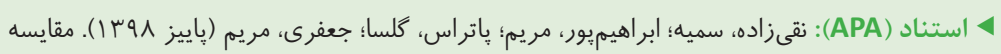

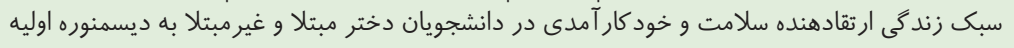

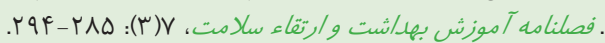

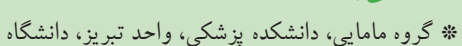
آزاد اسلامى، تبريز، ايران. (نو يسنده مسئول):

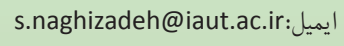

$$
\text { مريم ابر اهيميور تصيتر }
$$

كميته تحقيقات دانشجويى، واحد تبريز، دانشكاه آزاد

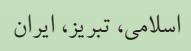

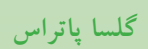
كميته تحقيقات دانشجويى، واحد تبريز، دانشكاه آزاد

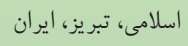

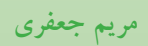
كميته تحقيقات دانشجويى، واحد تبريز، دانشكاه آزاد اسلامى، تبريز، ايران

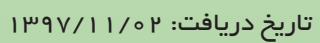

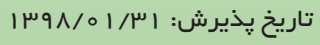


ايجاد استرس و اضطراب و فشارهاى روانى تأثير خذار باشد و به

دنبال آن باعث تشديد ديسمنوره مىشود (T) (Y). ارتقاى سلامت فرايندى براى توانمندساختن افراد به منظور

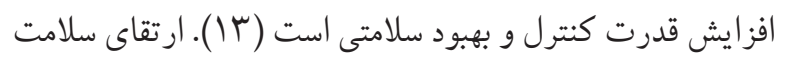
فقط بر عهدء بخش بهداشت نيست، بلكه فراتر مىرود و به سبك

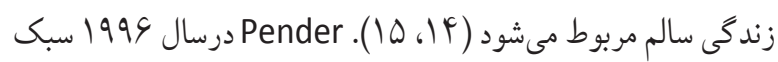
زندگى ارتقادهندة سلامت را در شش بُعد تغذيه، فعاليت فيز يكى، ردي، كنترل استرس، روابط بينفردى، خودشكوفايى و مسئوليت يذيرى

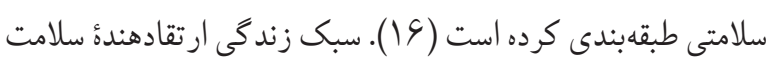

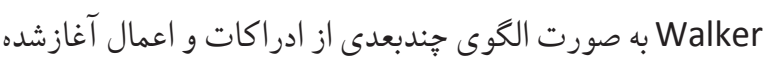
با انگيزه خود شخص تعريف مىشود كه به تداوم و تقويت سطح

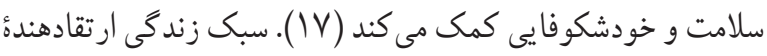
سلامت، راهكارهايى براى حفظ و ارتقاى سلامت است و يكى از

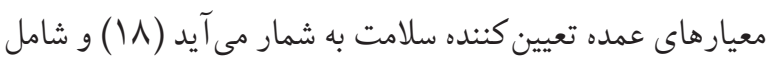
فرايندهايى است كه باعث افزايش تو انايىهاى فردى و كنترل فرد بر رفتارهاى سلامتى خود مىشود (1) 19، 19).

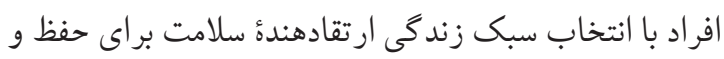

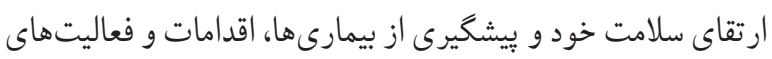

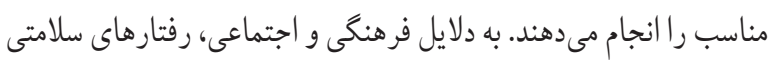
در كشورهاى مختلف متفاوت است؛ به طورى كه نتايج متناقضى

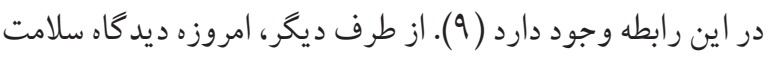

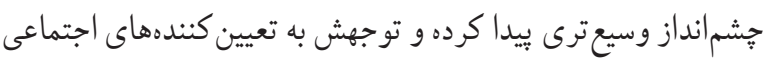
مؤثر بر سلامت معطوف شده است. هر يك از اين تعيين كنندها به خودى خود و يا از طريق تأثير بر يكديخر، وضعيت سلامتى را

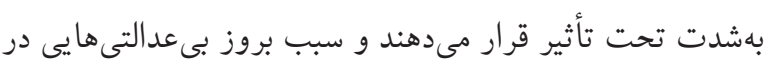
وضعيت سلامت مىشوند ( (Y).

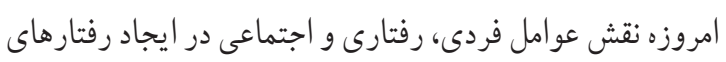

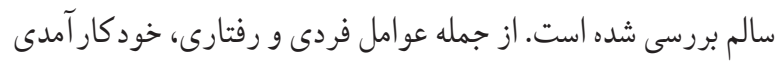

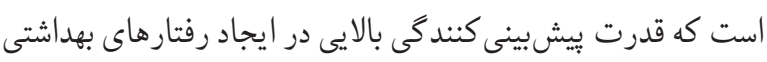

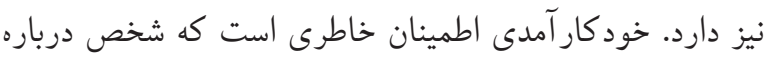

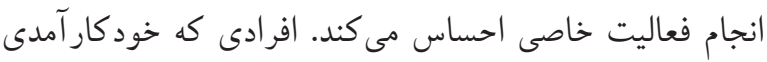

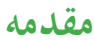

ديسمنوره اوليه يكى از شايعترين دردها و بيمارىهاى زنان است

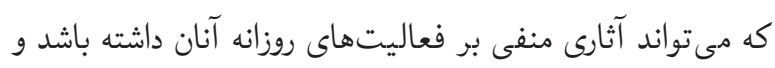

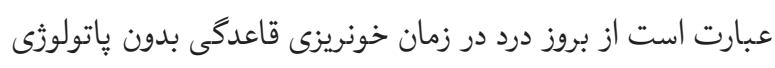

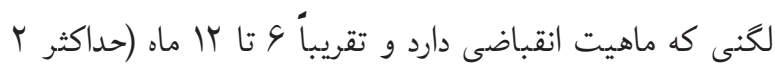

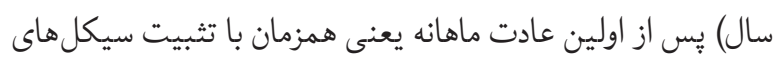
تخمك گذارى شروع مى شود ( (). ديسمنوره يا قاعدگى دردناك اوليه

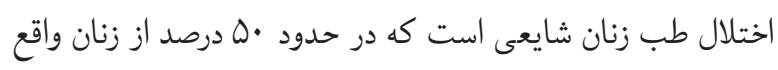

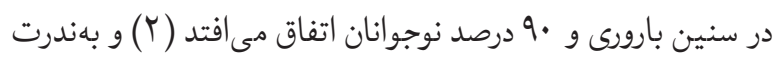

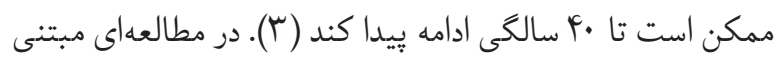

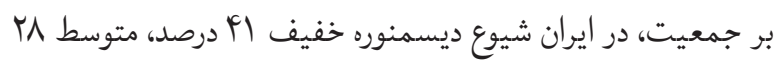
درصد و شديد با درصد گزارش شده است و نشان داده شد كه زنان جوان در مقايسه با زنان سنين بالاتر درد بيشترى را تجربه مى كنند

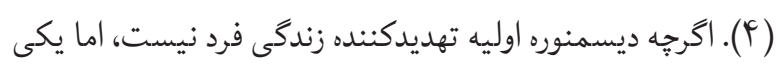
از عوامل اصلى مختل كننده كيفيت زندكى و فعاليت اجتماعى زنان است (ه) و از علل مهم غيبت هاى كوتاه مدت و مككرر دختران نوجوان، كاهش فعاليتهاى ورزشى و ايجاد محدوديت هاى اجتماعى است

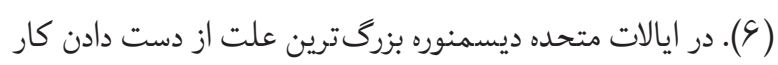

$$
\text { و مدرسه گزارش شده است (V) (Y). }
$$

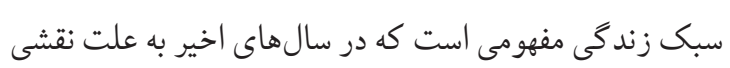

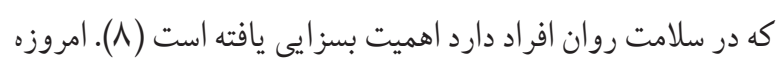
علت بسيارى از بيمارى هاى مزمن، سبك زندكى و رفتارهاى انسان

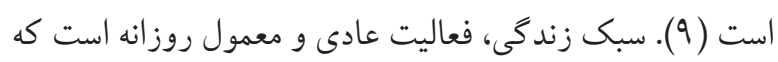

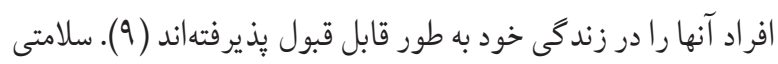

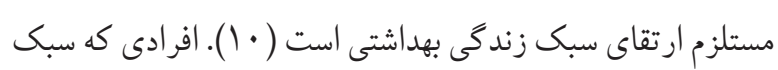

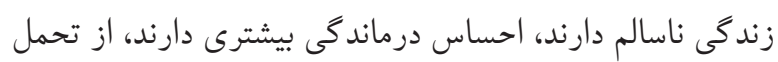

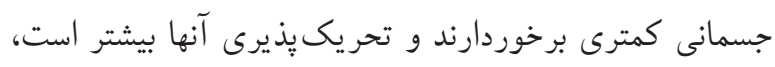

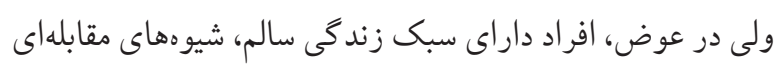

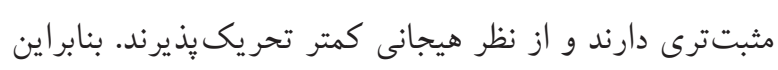

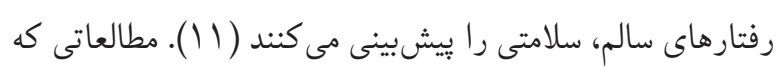

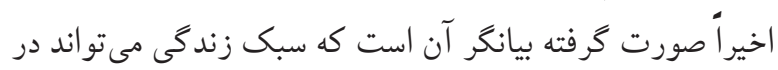


شد. اين تعداد با توجه به مطالعه Jamshidi و همكاران (19.19) و و بر اساس فرمول برآورد دو ميانگين به دست آمد. $\mathrm{n}=\frac{\left(Z_{1-\alpha / 2}+Z_{1-\beta}\right)^{2} \times S D^{2}}{d^{2}}$

بادر نظر گرفتن بزرگترين انحر اف معيار براى كيفيت زندگى،

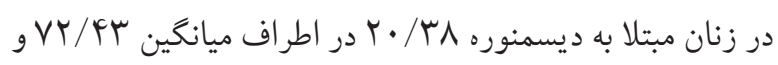

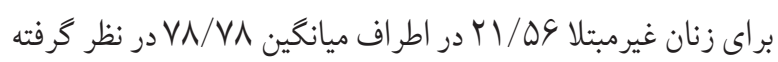

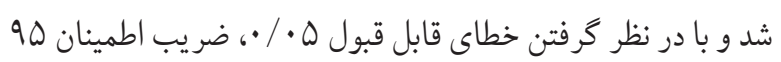

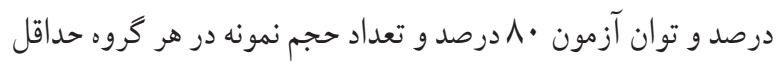

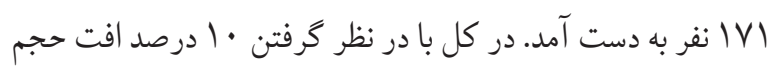

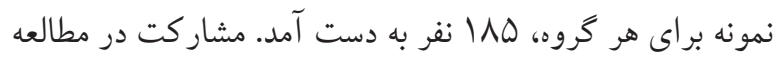
داوطلبانه و مبتنى بر رضايت بود و شر كت كنند مان مى تو انستند

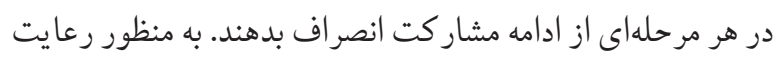
حريم خصوصى، مشخصات هويتى مشار كت كنند كان ثبت نشد.

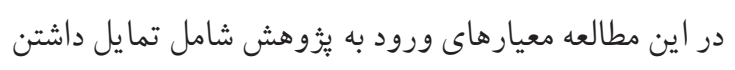
دانشجو يان براى شركت در يُوهش، داشتن و ماه قاعدگى دردناى

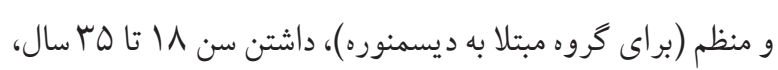

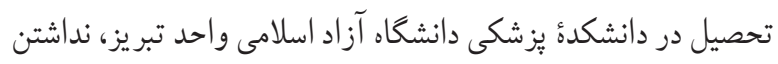

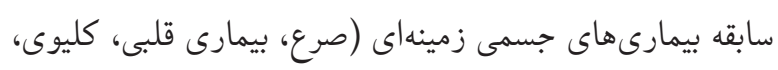

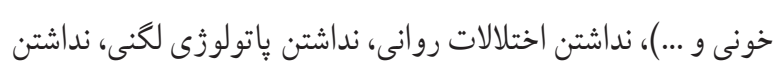

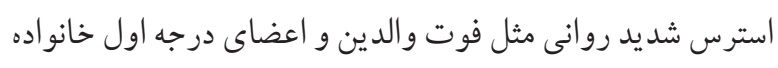

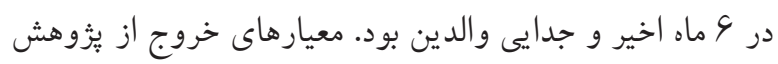
شامل تمايل نداشتن به ادامه شر كت در مطالعه بود.

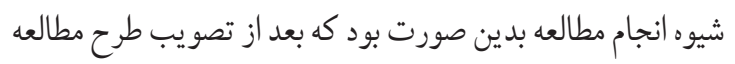

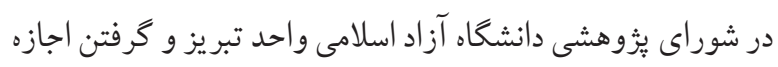

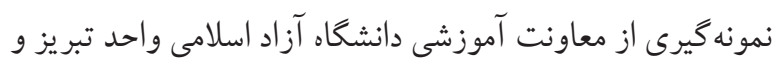

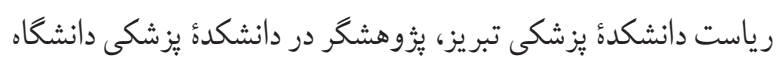

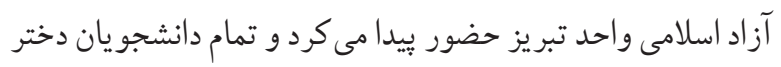

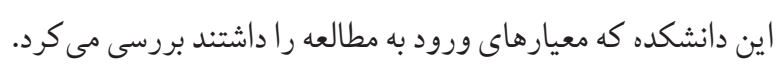
ابزار جمع آورى دادهها در اين مطالعه بِرسشنامه جهار قسمتى بود.

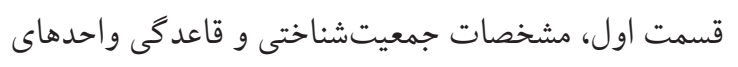

بولائى دارند، به كمك بهبود مهارتهاى خودمديريتى و پشتكار

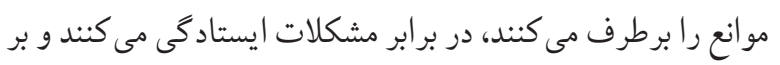

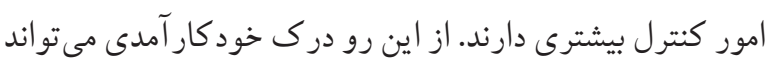
باعث حفظ و نكهدارى رفتارهاى ارتقادهندة سلامت شود ( (Y).

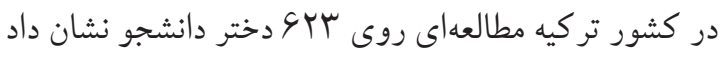

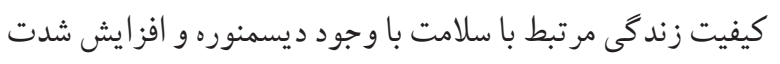

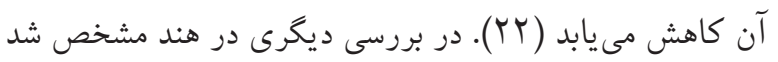
ديسمنوره مى تو اند اثرى منفى بر كيفيت زندكى دانشجو يان داشته

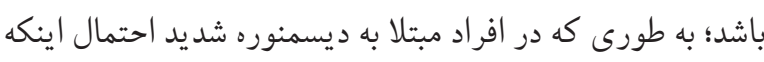

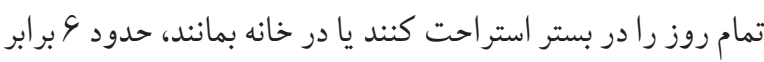

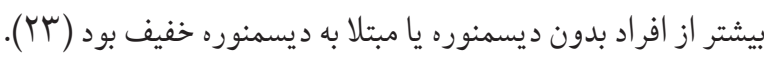
بررسى ديكرى در كشور تركيه روى צr Y دانشجوى بزشكى نشان

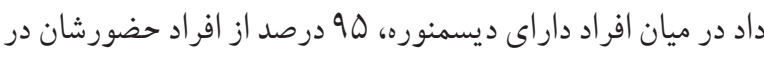
كلاس مختل بود و در درس تمركز ضعيفى داشتند (YY).

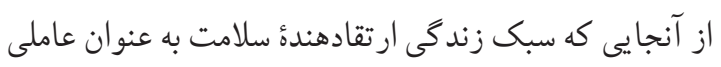
كليدى در سلامت، توجه گستردماى را در تحقيقات به خود جلب

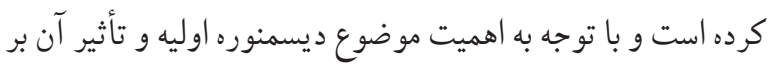
فعاليتهاى روزمره افراد و كمبود تحقيقات در اين زمينه و عوامل

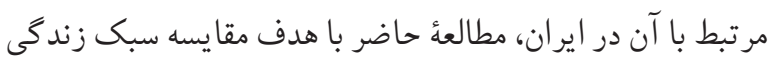
ارتقادهنده سلامت و خود كار آمدى در دانشجو يان مبتلا و غيرمبتلا به ديسمنوره اوليه در شهر تبريز انجام گرفت. مو اد و ورش مها

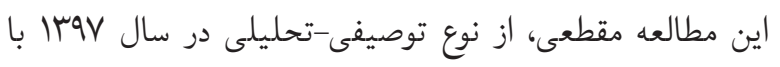

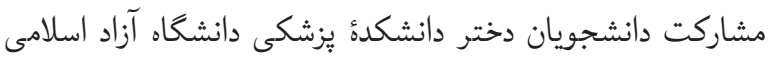

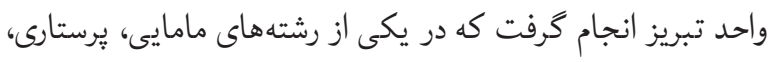

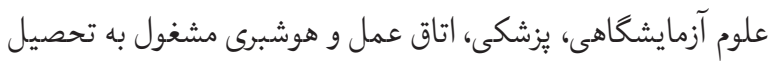
بودند. نمونه گيرى به صورت دردسترس انجام گرفت. افرادى كه نمره

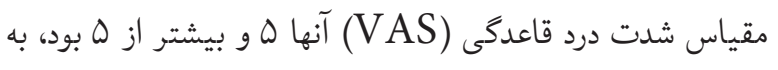
عنوان مبتلا به ديسمنوره اوليه و كمتر از له به عنوان غيرمبتلا در نظر كرفته شد. حجم نمونه در اين مطالعه •rr نفر در نظر كرفته 
هر سؤال بر اساس مقياس ليكرت از دامنه كاملاً مخالفم تا كاملاً

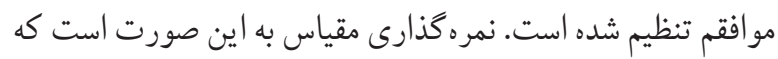

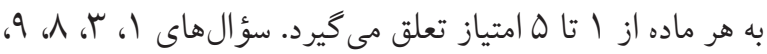

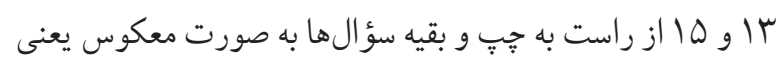

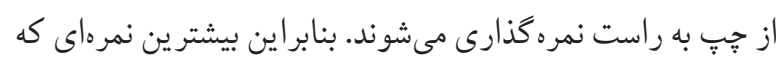

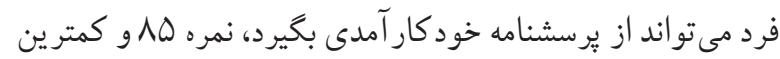

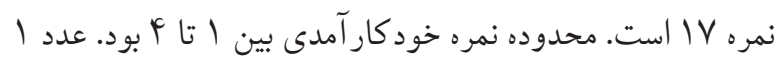

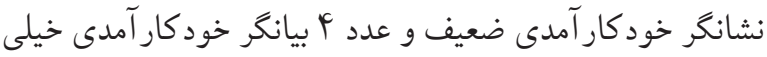
خوب بود. براتى (1999) اين مقياس را ترجمه و اعتباريابى و ضريب

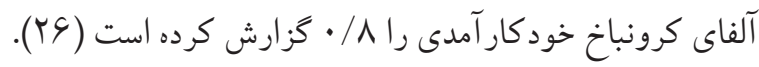

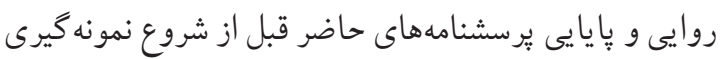

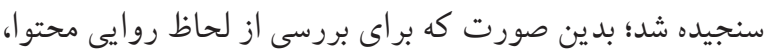

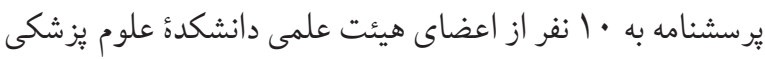

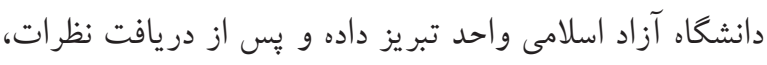

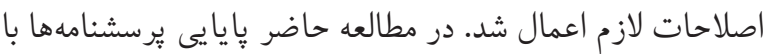

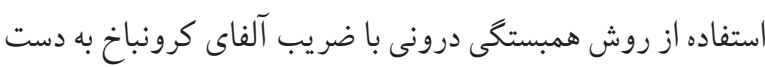

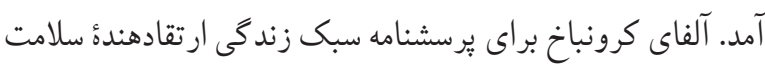

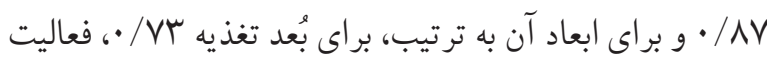

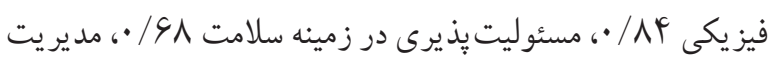

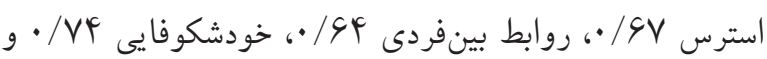

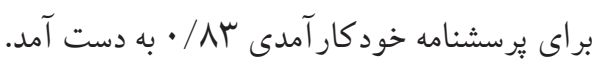

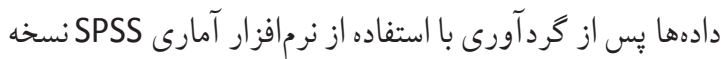
اب تجزيه تحليل شدند. به منظور توصيف مشخصات جمعيتشناختى

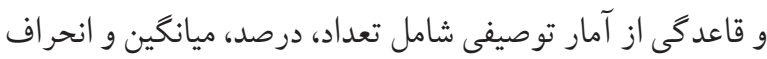
معيار و براى مقايسه مشخصات جمعيتشناختى و قاعدگى دو إنى

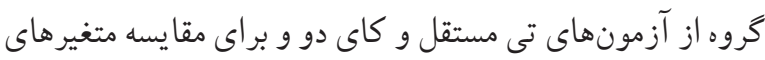

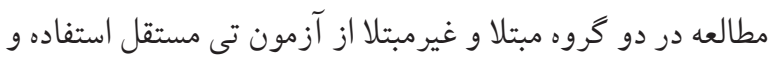
ه • • م معنى > P-value

بافتهها يافته ها حاكى از آن است كه ميانگين (انحراف معيار) سن دانشجويان
يُزوهش را بررسى مى كند كه شامل سن، وزن، قد، رشته و ترم تحصيلى، تحصيلات بدر و مادر، قوميت، وضعيت تأهل، وضعيت مالى، وضعيت ورزش، مصرف دخانيات و حساسيت دارويى و و غذايى و مشخصات قاعدگى شامل سن منارك، زمان شروع دردهاى ونى

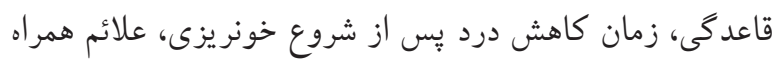
ديسمنوره، نوع داروى مسكن مصرفشده، كاهش درد قاعدگى به دن دنبال مصرف مسكن، بهبو د درد با ماساز و شدت دردهاى قاعدگى است. قسمت دوم، مقياس شدت درد قاعدكى (VAS) بود. ابتدا اين ابزار در اختيار دانشجويان قرار داده شد تا شدت ديسمنوره تعيين شود. مقياس

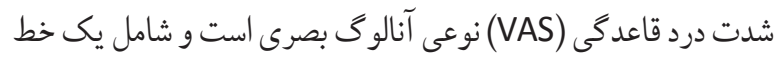

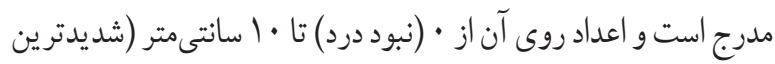
درد قابل تصور) براساس ميلىمتر درجهبندى شده است. ملاك شدت

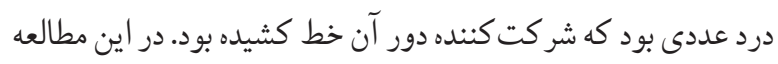

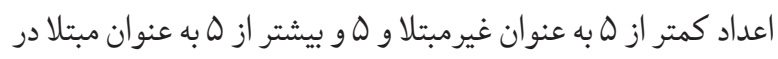

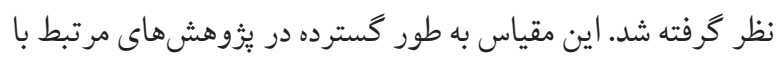
درد استفاده و روايى و يايايى آن تأييد شده است.

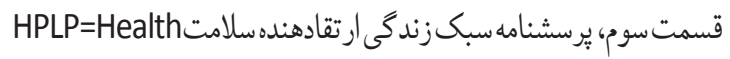

1911 است. Promotion Lifestyle-II

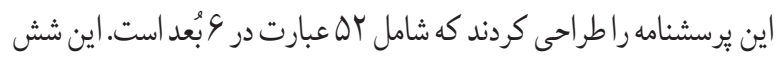

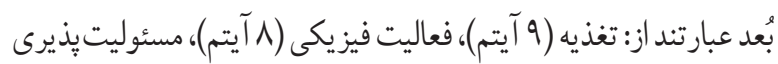

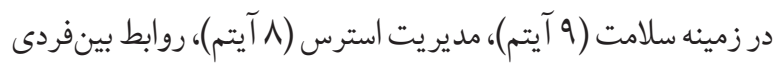
(9 آيتم) و خودشكوفايى (9 آيتم). تمامى آيتمها بر اساس مقياس ليكرت

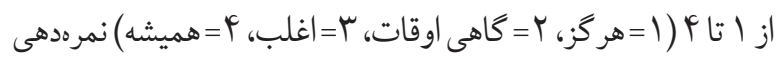

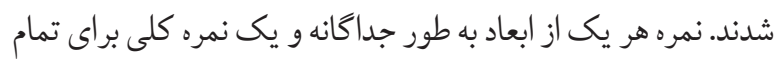

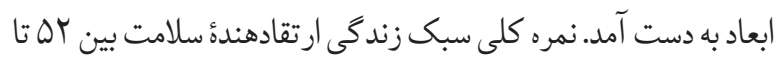

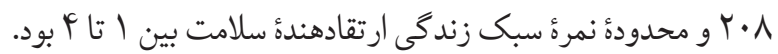

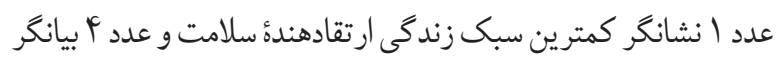

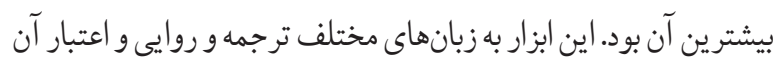

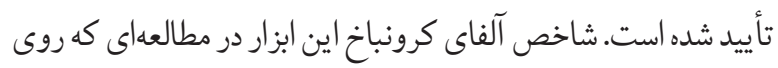

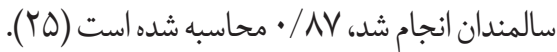
قسمت جهارم، برسشنامه خود كار آمدى است كه VI ل سؤال دارد. 


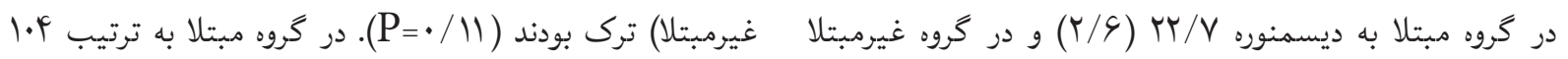

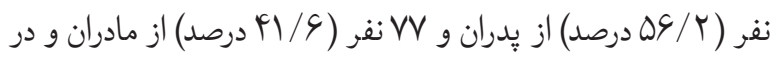

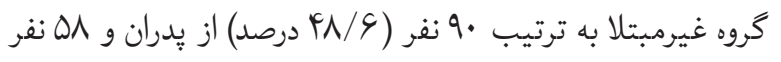

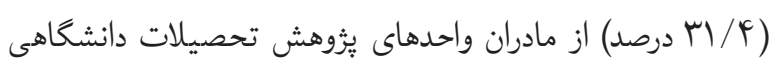

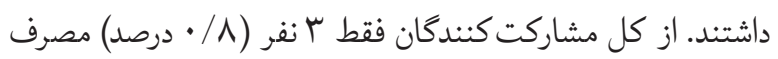

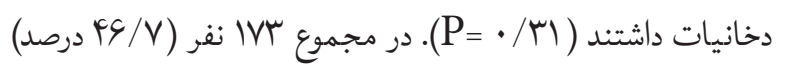

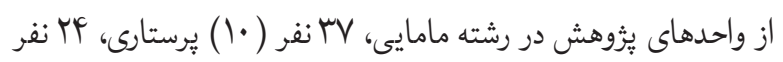

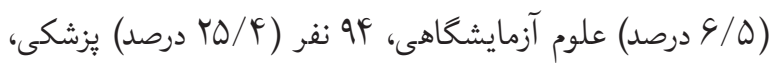

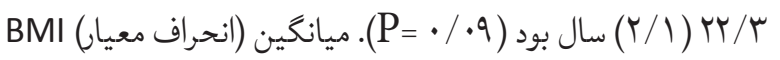
دانشجويان كروه مبتلا

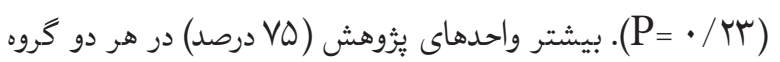

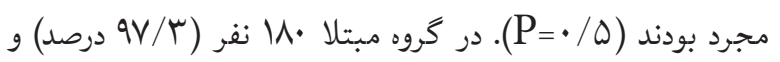

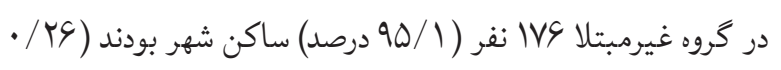

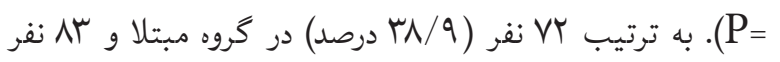

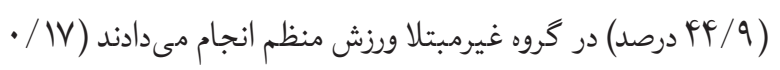
)

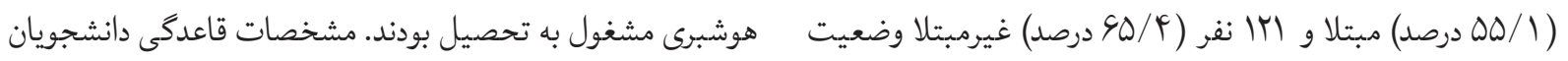

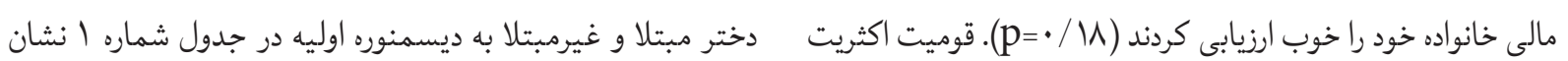

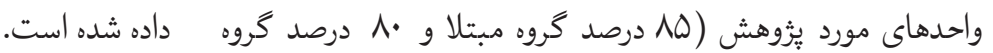
جدول ا. مشخصات قاعدگى دانشجويان دختر مبتلا و غير مبتلا به ديسمنوره اوليه

\begin{tabular}{|c|c|c|c|c|c|}
\hline 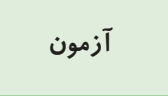 & $\begin{array}{l}\text { سطح معنىدارى } \\
\text { P-value }\end{array}$ & غيانغين (انحراف معيلا به ديسمنوره & ميانگين (انحراف معيار) & \multicolumn{2}{|c|}{ مشخصات قاعدگى } \\
\hline \multirow[t]{2}{*}{$=\cdot / T^{\mu}{ }^{r} *$} & $\cdot / \mathrm{V}^{\mu}$ & $\mid r / \Gamma(1 / \mu)$ & $\mid r / \mu(1 / f)$ & إ تا سا & سن اولين قاعدگى \\
\hline & & (درصد) فراوانى & (درصد) فراوانى & & \\
\hline \multirow[t]{3}{*}{$=\cdot / X r \mid V$ 米米 } & & $V \Delta(F \cdot / \Delta)$ & $V V(f \mid / \varepsilon)$ & ايا rروز قبل از شروع خونريزى & \\
\hline &.$/ 91$ & $\Delta 9(\pi / / 9)$ & $\Delta \Delta(Y q / Y)$ & هند ساعت قبل از شروع خونريزى & زمان شروع درد \\
\hline & & $\Delta \cdot(Y Y)$ & $\Delta \backslash(Y V / S)$ & بعد از شروع خونريزى & \\
\hline \multirow[t]{2}{*}{$=V / X r \Delta$} & $\cdot 1 \cdot 0$ & $\operatorname{Irr}(V \mid / F)$ & $\operatorname{l|V(\varsigma \mu /r)}$ & ( & زمان كاهش درد يس از \\
\hline & . & $\Delta r(r \wedge / Y)$ & $\varepsilon \wedge(r s / \vee)$ & ( & شروع خونريزى \\
\hline$=r \Delta / X r \Delta$ & $\cdot / \cdots 1$ & $11 \Delta(S T / Y)$ & $\operatorname{loV}(\Lambda F / q)$ & 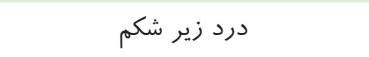 & \multirow{5}{*}{ علائم همراه ديسمنوره } \\
\hline$=|V / X r|$ &.$/ \cdots 1$ & $1 \cdot 1(\Delta F / s)$ & $1 \% q(V \Delta / 1)$ & درد كمر & \\
\hline$=\mid r / X r r$ & $\cdot / \cdots 1$ & $\Delta F(Y q / Y)$ & $\Lambda \Lambda(F \vee / S)$ & درد انتشاريابنده به ران & \\
\hline$=r \cdot|X r|$ & $\cdot 1 \cdots 1$ & $V Y(\Psi \wedge / ৭)$ & $\operatorname{ITF}(S V)$ & 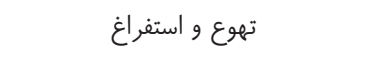 & \\
\hline$=1 / \mathrm{Xr \Delta}$ & $\cdot / 1 \mu$ & $\mu \cdot(\mid s / r)$ & $r q(Y \backslash /)$ & 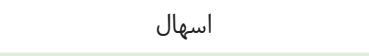 & \\
\hline \multirow{5}{*}{$=\mid \Delta / X r \cdot r$} & \multirow{5}{*}{$\cdot / \cdots \Delta$} & $\varphi(r / r)$ & $\Delta \cdot(Y Y)$ & 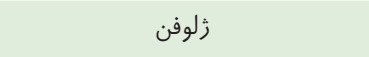 & \multirow{5}{*}{ نوع داروى مسكن } \\
\hline & & $I \mu(V)$ & $r \cdot(1 \varepsilon / r r)$ & مفناميك اسيد & \\
\hline & & $s(r / r)$ & $10(N / 1)$ & ايبويروفن & \\
\hline & & $1 \cdot(\Delta / \mathcal{F})$ & $19(1 \cdot / r V)$ & داروهاى گياهى & \\
\hline & & $F(Y / Y)$ & $F \Delta(Y F / \Psi)$ & ساير (هيوسين، ديكلوفناك و ...) & \\
\hline \multirow{4}{*}{$=r \mid / X r \cdot q$} & \multirow{4}{*}{$\cdot / \cdots 1$} & $S \Delta(r \Delta / 1)$ & $\Delta \cdot(Y Y)$ & هميشه & \multirow{4}{*}{ كاهش درد قاعدگى به مصرف مسكن } \\
\hline & & $G \mathcal{F}(\mathbb{F} / G)$ & $1 \cdot \Delta(\Delta S / \Lambda)$ & 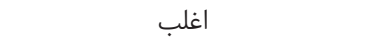 & \\
\hline & & $r G(\mid r / I)$ & $19(1 \cdot / \mu)$ & 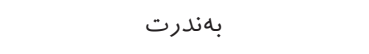 & \\
\hline & & $19(1 \cdot / \mu)$ & $\Delta(Y / V)$ & هر خز & \\
\hline$=r / X r r \Delta$ & $\cdot / \cdot r$ & $11 \cdot(\Delta 9 / F)$ & $9 \varsigma(\Delta) / \wedge)$ & & بهبود درد با ماساز \\
\hline
\end{tabular}


ميانكين (انحر اف معيار) سبك زندگى ارتقادهندة سلامت در دو گروه دانشجويان مبتلا و غيرمبتلا به ديسمنوره تفاوت آمارى

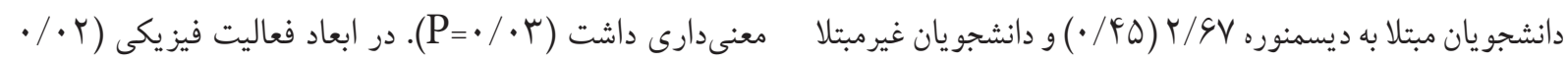

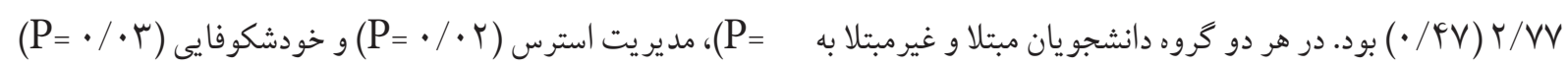

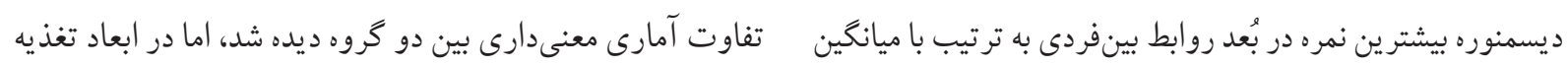

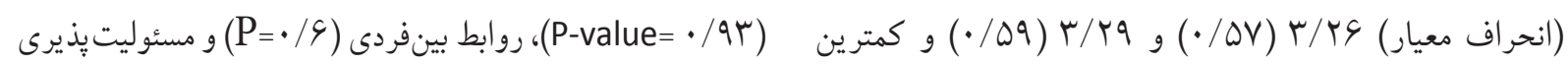

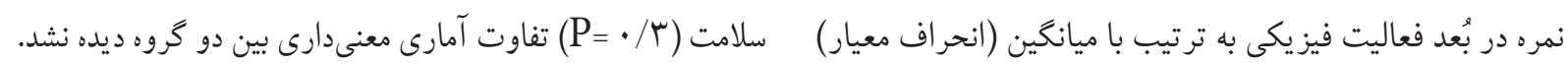

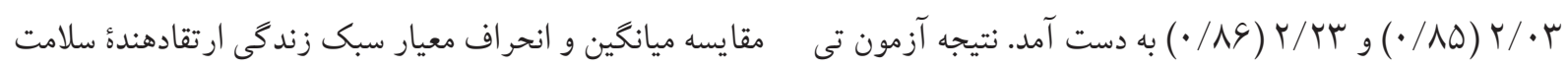

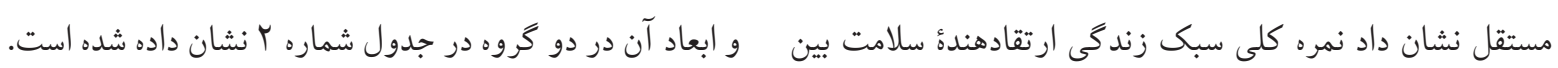

جدول r. مقايسه ميانگين و انحراف معيار سبك زندگى ارتقادهندة سلامت در دانشجويان مبتلا و غيرمبتلا به ديسمنوره

\begin{tabular}{|c|c|c|c|c|}
\hline $\begin{array}{c}\text { آزمون } \\
\text { T } * \text { }\end{array}$ & $\begin{array}{l}\text { سطح معنىدارى } \\
\text { P-value }\end{array}$ & غيانغين (انحراف معيتلا به ديسمنوره & ميانكين (انحراف معيار) & سبك زندگى ارتقادهنده سلامت \\
\hline$r / \cdot \Lambda$ & $\cdot / \cdot r$ & $(\cdot / \mathcal{F V}) \mathrm{r} / \mathrm{VV}$ & $(\cdot / \mathcal{F} \Delta) Y / S V$ & نمره كلى سبك زندگى ارتقادهنده سلامت \\
\hline$\cdot / \Lambda$ & $\cdot / 94$ & $(\cdot / 9 \Lambda) r / \Lambda r$ & $(\cdot / 91) r / A r$ & ت تغذيه \\
\hline$\cdot / 4$ & $\cdot / 4$ & $(\cdot / \Delta q) r / r q$ & $(\cdot / \Delta V) r / r \varepsilon$ & روابط بينفردى \\
\hline 1 & $\cdot / \mu$ & $(\cdot / G \Lambda) r / F r$ & $(\cdot / 9 \Delta) r / r \Delta \Delta$ & مسئوليتيذيرى سلامت \\
\hline$r / r$ & $\cdot / \cdot r$ & $(\cdot / \Lambda s) r / r \mu$ & $(\cdot / \Lambda \Delta) r / \cdot r$ & فعاليت فيزيكى \\
\hline$r / \mu$ & $\cdot / \cdot r$ & $(\cdot / 9 \wedge) r / V I$ & $(\cdot / 9 \Delta) r / \Delta \Delta$ & 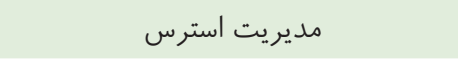 \\
\hline$r / l$ & $\cdot / \cdot \mu$ & $(\cdot / s \mu) \Psi / I V$ & $(\cdot / 90) \mu / \cdot r$ & خودشكوفايى \\
\hline
\end{tabular}

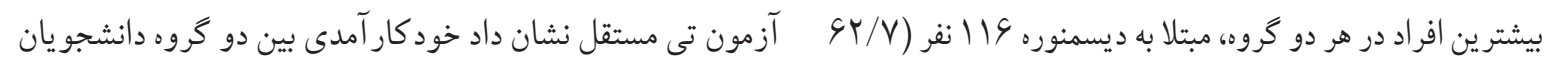

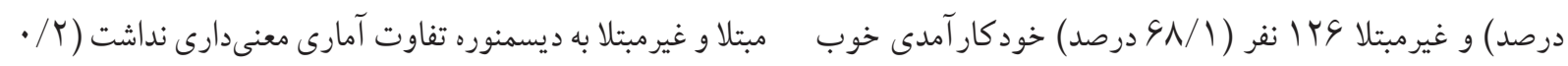

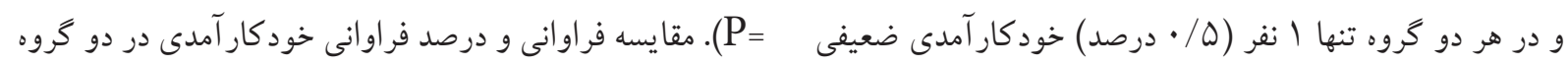

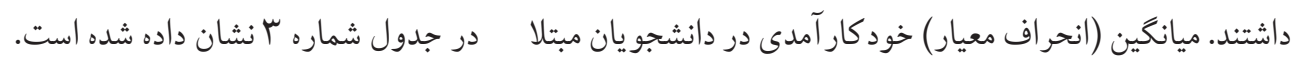

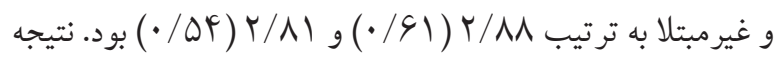
جدولس. مقايسه فراوانى و درصد فراوانى خود كارآمدى در دانشجويان مبتلا و غيرمبتلا به ديسمنوره

\begin{tabular}{|c|c|c|}
\hline غيرمبتلا به ديسمنوره & فبتلا به ديسمنوره & خود كار آمدى \\
\hline $1(\cdot / 0)$ & $1(\cdot / 0)$ & ضعيف \\
\hline$F G(Y Y / q)$ & $\mathcal{F F}(r \mu / \Lambda)$ & متوسط \\
\hline $\mid r G(G \wedge / 1)$ & $\| \varsigma(S T / V)$ & خوب \\
\hline$I r(s / \Delta)$ & $r F(\mid r)$ & خيلى خوب \\
\hline
\end{tabular}


شهر اهواز بيشتر ين ميانخين ابعاد سبك زندگى ارتقادهندء سلامت

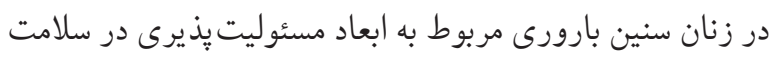

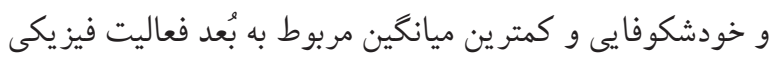
بوده است (9 (1). در مطالعه حاضر و ساير مطالعات، كمتر ين نمره سبك زندگى ارتقادهندهُ سلامت مر بوط به بُعد فعاليت فيزيكى است. كمبود فعاليت فيزيكى در جوامع ما، در كروههاى مختلف زنان بنان

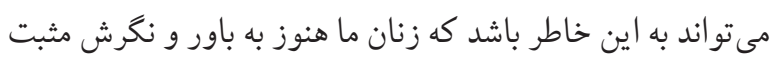
نسبت به انجام فعاليت فيز يكى -جسمانى نرسيدهاند. كارشناسان عقيده دارند اخر فرد نكرش مثبتى نسبت به يك رفتار داشته باشد، آن رفتار را انجام خواهد داد ( •r).

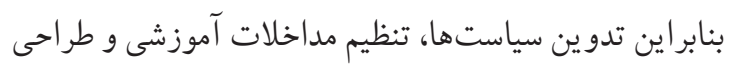
راهبردهايى به منظور ارتقاى فعاليت فيزيكى ضرورى به نظر مى رسد.

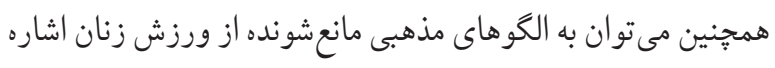

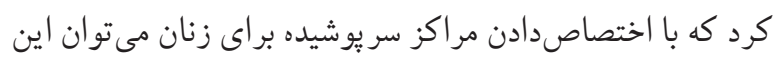

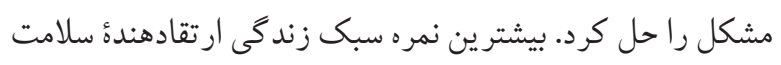
در مطالعات مختلف متغير بود. تفاوت در نتايج اين مطالعات

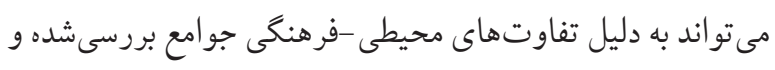
جامعه آمارى مختلف باشد. ميانخين خود كار آمدى در دانشجو يان مبتلا و غيرمبتلا به ترتيب

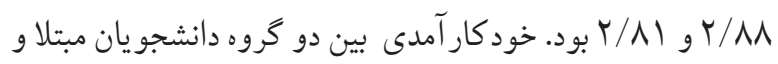

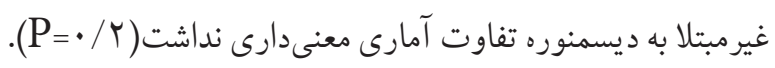

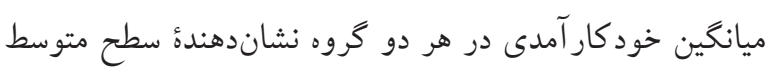

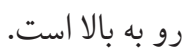

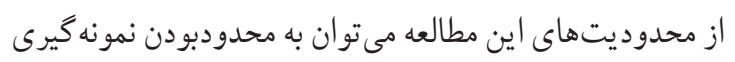

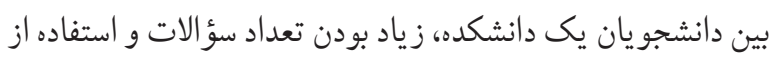

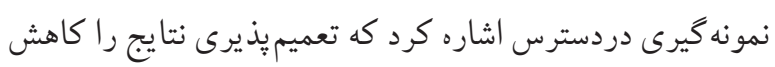

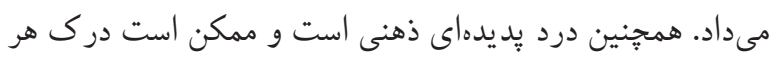

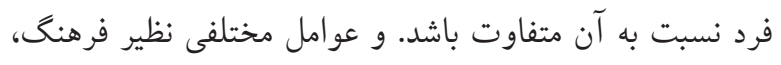

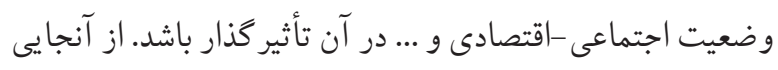
كه ديسمنوره موجب مشكلات اجتماعى، اقتصادى، جسمانى و وصيو
يافتهاى حاصل از يُزوهش حاضر بيانكر آن است كه نمره كلى

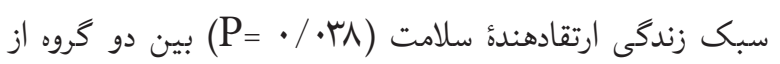

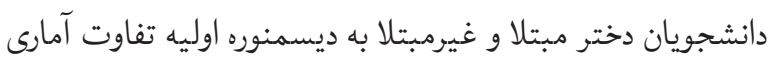

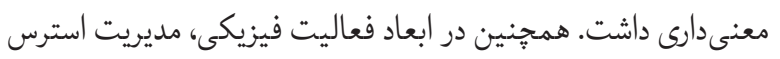

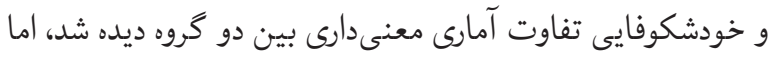

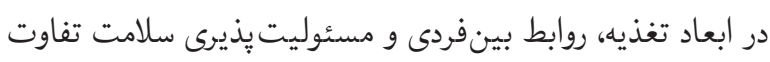

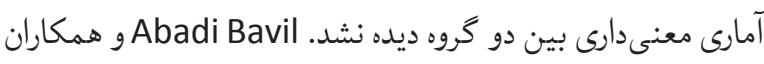

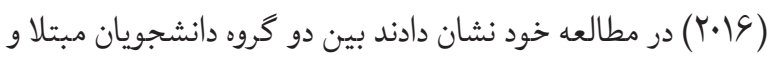

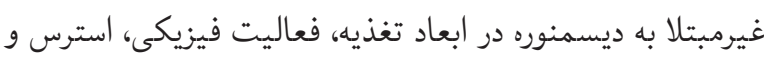

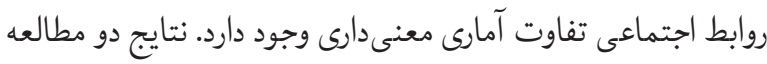
در بُعد فعاليت فيزيكى و استرس همسو بودند (YV)

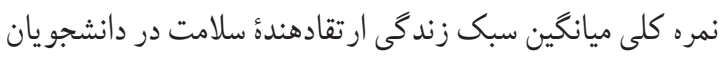

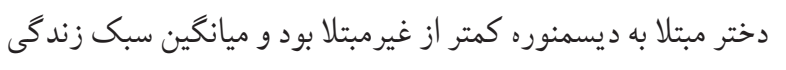
ارتقادهندة سلامت در هر دو گروه نشاندهنده سطح متوسط رو به به بالا

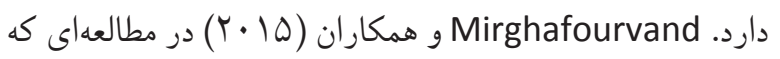
در ايران روى زنان سنين بارورى انجام دادند، نمره كلى رفتارهاى

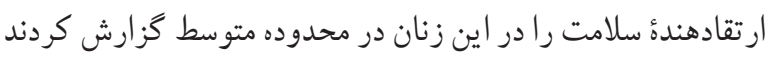

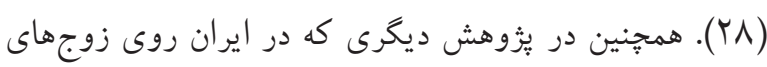

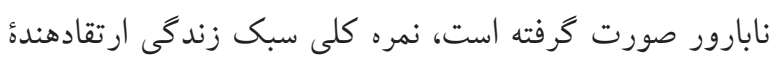

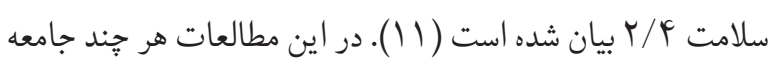

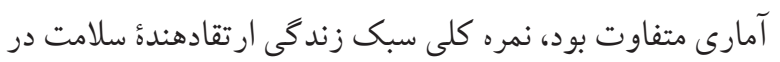
حد متوسط بود. در هر دو گروه دانشجو يان مبتلاو غير مبتلا به ديسمنوره بيشترين

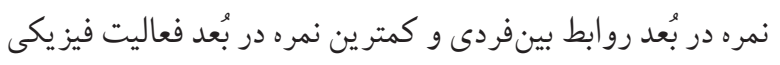

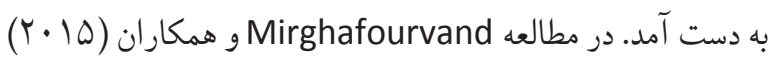

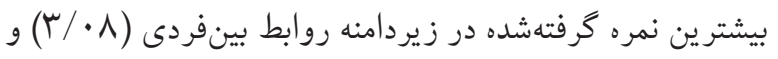

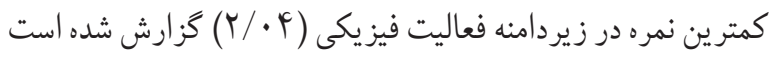

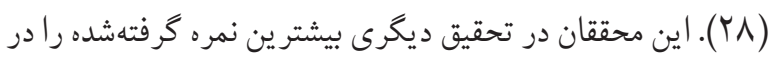

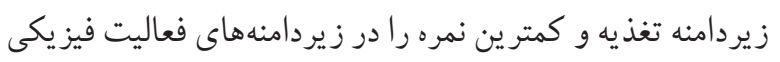

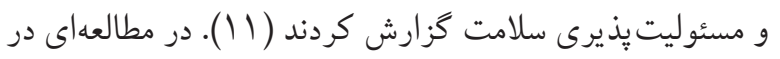


افزايش آكاهى، آموزش و ارائه راهكارهاى مناسب به اين دختران در زمينه ارتقاى سبك زندكى سالم و به دنبال آن، بهبود كيفيت آنس آنه زندكى مى توان كمك شايانى به اين افراد كرد.

$$
\text { تقدير و تشكر }
$$

از همكارى معاونت يثوهش و فناورى و دانشكده يزشكى دانشعاه

آزاد اسلامى واحد تبريز تشكر و قدردانى مى شود. مطالعه حاضر

حاصل طرح تحقيقاتى مصوب دانشخاه آزاد اسلامى واحد تبريز با كد اخلاق IR.IAU.TABRIZ.REC.1397.011 است.

$$
\text { تضاد منافع تمارض منامى نويسندگان در اين مطالعه يكسان است و هيج كونه }
$$

\section{References}

1. Mohammadi B, Azamian Jazi A, Fathollahi Shourabeh F. The Effect of Aerobic Exercise Training and Detraining on Some of the Menstrual Disorders in Non-Athlete Students in Lorestan Universities. The Horizon of Medical Sciences. 2012; 18(2):5-12.

2. Berek JS NE. Berek and Novak's Gynecology. Philadelphia: Lippincott Williams \& Wilkins; 2012.

3. Darabi R, Aghamohammadi H, Jafari A, Sadegifard $F$, Haccopian G. Efficacy of Accupuncture in Control of Primary Dysmenorrhea Related Pain in 15-30 Years Old Women at the Gynecology Clinic of Bouali Hospital Between 2007 and 2008. Journal of Medical Sciences. 2010; 20(3):170-174.

4. Tavallaee M, Joffres MR, Corber SJ, Bayanzadeh M, Rad MM. The Prevalence of Menstrual Pain and Associated Risk Factors Among Iranian Women. Journal of Obstetrics and Gynaecology Research. 2011; 37(5):442-451. https://doi.org/10.1111/j.1447-0756.2010.01362.x PMid:21208343

5. Burnett MA, Antao V, Black A, Feldman K, Grenville $A$, Lefebvre $G$,et al. Prevalamce of Primary Dysmenorehea in Canada. Journal of Obstetrics and Gynacologycanada. 2005; 27(8):765-770. DOI: https://doi.org/10.1016/S1701-2163(16)30728-9 https://doi.org/10.1016/S1701-2163(16)30728-9

6. French L. Dysmenorrhea. American Family Physician. 2005; $71(2): 285$.

7. Kumbhar SK, Reddy M, Sujana B, Reddy RK, Bhargavi DK, Balkrishna C. Prevalence of Dysmenorrhea Among Adolescent Girls (14-19 yrs) of Kadapa District and Its Impact on Quality of Life: A Cross Sectional Study. National
روانى كستردهاى مىشود، ييشنهاد مىشود مطالعات مشابهى در ديخر مناطق جغرافيايى كشور انجام كيرد، ساير تعيين كنندهاى اجتماعى سلامت بر روى دختران مبتلا به ديسمنوره بررسى شود، تأثير شيوههاى مختلف آموزشى (مانند بيامهاى تلفنى كو تاه، يمفلتهاى آموزشى، سىدىهاى آموزشى) بر بهبود سبك زندكى ارتقادهنده سلامت دانشجويان مبتلا به ديسمنوره بررسى شود. همجنين اين تعيين كنندهاى اجتماعى سلامت بر روى ديخر كروههاى زنان و دختران بررسى شود. نتيجان كيرى

نتايج مطالعه نشان داد در دختران مبتلا به ديسمنوره نمره كلى سبك زندكى ارتقادهنده سلامت كمتر از دختران غيرمبتلا بود. بنابراين با

Journal of Community Medicine. 2011; 2(2):265-268.

8. Jamshidi F, Amir AA, Afrakhteh M, Talebi A. Comparing the Quality of Life in Women With and Without Primary Dysmenorrhea and Pain Reduction Strategies in Patients Referred to Shahid Beheshti Health Centers Affiliated With the University of Medical Sciences in Tehran in 1393. Journal Shahid Beheshti University of Medical Sciences. 2016; 26(92):47-57.

9. Baheiraei A, Mirghafourvand M, Mohammadi E, Charandabi SM. The Experiences of Women of Reproductive Age Regarding Health-Promoting Behaviours: A Qualitative Study. BMC Public Health. 2012; 12(1):573. https://doi.org/10.1186/1471-2458-12-573 PMid:22846587 PMCid:PMC3490730

10. Tol A, Tavassoli E, Shariferad GR, Shojaezadeh D. The Relation Between Health-Promoting Lifestyle and Quality of Life in Undergraduate Students at School of Health, Isfahan University of Medical Sciences. Health System Research; 2011; 7(4).

11. Mirghafourvand M, Sehhati F, Rahimi M. Health-Promoting Lifestyle and Its Demographic Predictors in InfertileCouples Referred to Infertility Clinic of Tabriz Al-Zahra Hospital, 2013. Journal of Caring Sciences. 2014; 3(3):175-184.

12. Samiei Siboni F, Alimoradi Z, Sadegi T. Impact of Corrective Life Style Education Program on Controlling Stress Anxiety, and Depression in Hypertensive. Journal of Birjand University of Medical Sciences. 2013; 19(6):1-9.

13. Chang EY, Kim JS, Shin SJ. Health Promotion Lifestyle According to Self Perception of Obesity and Objective Status Measured by Bioelectric Impedance Analysis in College Women. Journal of 
Korean Academy of Nursing. 2009; 39(5):693-699. https://doi.org/10.4040/jkan.2009.39.5.693 PMid:19901499

14. Cooper SM, Guthrie B. Ecological Influences on HealthPromoting and Health-Compromising Behaviors: A Socially Embedded Approach to Urban African American Girls' Health. Family \& Community Health. 2007; 30(1):29-41. https://doi.org/10.1097/00003727-20070100000005

15. Corral L, Landrine H. Racial Discrimination and Health-Promoting vs. Damaging Behaviors Among African-American Adults. Journal of Health Psychology. 2012; 17(8):1176-1182. https://doi.org/10.1177/1359105311435429 PMid:22313668

16. Motlagh Z, Mazloomy-Mahmoodabad S, Momayyezi M. Study of Health-Promotion Behaviors Among University of Medical Science Students. Zahedan Journal of Research in Medical Sciences. 2011; 13(4):29-34.

17. Walker SN, Kerr MJ, Pender NJ, Sechrist KR. A Spanish Language Version of the Health-Promoting Lifestyle Profile. Nursing Research. 1990; 39(5):268-273. https://doi.org/10.1097/00006199$\begin{array}{lllllllllllllll}1 & 9 & 9 & 0 & 0 & 9 & 0 & 0 & 0 & - & 0 & 0 & 0 & 0 & 3\end{array}$ PMid:2399130

18. Kamrani Rad Z, Attarian F. Health-Promoting Lifestyle Among Mashhad School of Health Students, Mashhad, Iran, 2014. Journal of Midwifery and Reproductive Health. 2014; 2(3):195-204.

19. Procter SB, Campbell CG. Position of the Academy of Nutrition and Dietetics: Nutrition and Lifestyle for a Healthy Pregnancy Outcome. Journal of the Academy of Nutrition and Dietetics. 2014; 114(7):1099-1103. https://doi.org/10.1016/j.jand.2014.05.005 PMid:24956993

20. Marmot MG, Bell R. Action on Health Disparities in the United States: Commission on Social Determinants of Health. JAMA. 2009; 301(11):1169-1171. https://doi.org/10.1001/jama.2009.363 PMid:19293419

21. Roosta F, Ahmadi A. Self-Efficacy and Health Promoting Behaviors Among Women of Reproductive Ages in Shiraz During 2013. Journal of llam University of Medical Sciences. 2016; 24(2):90-100 https://doi.org/10.18869/acadpub.sjimu.24.2.90

22. Unsal A, Ayranci U, Tozun M, Arslan G, Calik E. Prevalence of Dysmenorrhea and Its Effect on Quality of Life
Among a Group of Female University Students. Upsala Journal of Medical Sciences. 2010; 115(2):138-145. https://doi.org/10.3109/03009730903457218 PMid:20074018 PMCid:PMC2853792

23. Charu S, Amita R, Sujoy R, Thomas GA. 'Menstrual Characteristics' and 'Prevalence and Effects of Dysmenorrhea' on Quality of Life of Medical Students. International Journal of Collaborative Research on Internal Medicine \& Public Health. 2012; 4(4):276-294.

24. Oral E, Kirkan T, Yazici E, Cansever MG, Aydin N. Premenstrual Symptom Severity, Dysmenorrhea, and School Performance in Medical Students. Journal of Mood Disorders. 2012; 2(4):143-152. https://doi.org/10.5455/jmood.20120912035016

25. Morowatisharifabad MA, Ghofranipour F, Heidarnia A, Ruchi GB, Ehrampoush MH. Self-Efficacy and Health Promotion Behaviors of Older Adults in Iran. Social Behavior and Personality: An International Journal. 2006; 34(7):759-768. https://doi.org/10.2224/sbp.2006.34.7.759

26. Barati Bakhtyari S. Investigating the Simple and Multiple Relationship Between Self-Efficacy, Self-Esteem and SelfDiscovery Variables With Academic Performance in Third Year High School Students in Ahvaz City. MSc thesis. Ahvaz: Shahid Chamran University of Ahwaz; 1996.

27. Abadi Bavil D, Dolatian M, Mahmoodi Z, Akbarzadeh Baghban A. Comparison of Lifestyles of Young Women With and Without Primary Dysmenorrhea. Electronic Physician. 2016; 8(3):2107-2114. h tt p s : / / d o i . org / 10.19082 / 2107 PMid:27123219 PMCid:PMC4844476

28. Mirghafourvand M, Baheiraei A, Nedjat S, Mohammadi E, Charandabi SM, Majdzadeh R. A Population-Based Study of Health-Promoting Behaviors and Their Predictors in Iranian Women of Reproductive Age. Health promotion international. 2014; 30(3):586-594. https://doi.org/10.1093/heapro/dat086 PMid:24395956

29. Abedi P, Jorfi M, Afshari P. Evaluation of the Health Promotion Lifestyle and Its Related Factors in Reproductive Aged Women in Ahvaz, Iran. Community Health Journal. 2017; 9(1):68-74.

30. Tuteja AK, Talley NJ, Joos SK, Woehl JV, Hickam DH. Is Constipation Associated With Decreased Physical Activity in Normally Active Subjects?. The American Journal of Gastroenterology. 2005; 100(1):124-129. https://doi.org/10.1111/j.1572-0241.2005.40516.x PMid:15654791 